\title{
RANCANG BANGUN DAPUR LEBUR ALUMINIUM KAPASITAS 20 KG SKALA LABORATORIUM
}

\author{
Din Aswan Amran Ritonga ${ }^{(1}$ \\ Program Studi Teknik Mesin, Sekolah Tinggi Teknik Harapan Medan, \\ Jl. H. M. Joni No. 70 C, Medan, Telp. (061) 7366804 \\ E-mail: din.aswan@gmail.com
}

\begin{abstract}
Sand casting is one of the techniques of making products where the metal melted in a crucible and then poured into the mold cavity which is similar to the original shape of the cast product to be made. At this time a lot of research, especially aluminum foundry with a variety of fuels such as diesel, kerosene, LPG gas, coal and so on, both among universities as well as in a industrial research. To be able to do metal casting it must be equipped with tools that support smelting. This has led the authors to conduct design molten aluminum furnance with a capacity of $20 \mathrm{~kg}$ to laboratory scale with LPG gas fuel, given the lack of facilities available at the Laboratory of Production Process Dept. Mechanical Engineering Sekolah Tinggi Teknik Harapan.The author conducted a literature study and field surveys to learn about and see models of aluminum furnance design during design process. From the results obtained planning buster kitchen with kitchen-type Crucible, a kitchen with a diameter of $560 \mathrm{~mm}, 520 \mathrm{~mm}$ height kitchen, outside of the cup $220 \mathrm{~mm}$ diameter, $20 \mathrm{~mm}$ thick plate, cup height $355 \mathrm{~mm}$.
\end{abstract}

Keywords: Sand casting, Crubicle, Aluminum, Fuel

\begin{abstract}
Abstrak
Pengecoran adalah salah satu teknik pembuatan produk dimana logam dicairkan dalam tungku peleburan kemudian dituangkan kedalam rongga cetakan yang serupa dengan bentuk asli dari produk cor yang akan dibuat. Pada saat ini banyak dilakukan penelitian pengecoran logam khususnya aluminium dengan berbagai macam bahan bakar seperti minyak solar, minyak tanah, gas LPG, batu bara dan sebagainya, baik dikalangan universitas maupun di suatu badan penelitian. Untuk dapat melakukan pengecoran logam maka harus dilengkapi dengan alat peleburan yang mendukung. Hal inilah yang mendorong penulis untuk melakukan perencanaan dapur lebur aluminium dengan kapasitas $20 \mathrm{~kg}$ untuk skala laboratorium dengan bahan bakar gas LPG, mengingat masih minimnya fasilitas yang tersedia di Laboratorium Proses Produksi Teknik Sekolah Tinggi Teknik Harapan. Dalam melakukan perancang dapur lebur ini, penulis melakukan studi literatur dan survey lapangan untuk mempelajari dan melihat model-model rancang bangun dapur alumunium. Dari hasil perencanaan diperoleh dapur pelebur dengan tipe dapur Crucible, dengan diameter dapur $560 \mathrm{~mm}$, tinggi dapur $520 \mathrm{~mm}$, diameter luar cawan $220 \mathrm{~mm}$, tebal cawan $20 \mathrm{~mm}$, tinggi cawan $355 \mathrm{~mm}$.
\end{abstract}

Kata kunci: Pengecoran Logam, Dapur lebur, Aluminium, Bahan Bakar.

\section{Pendahuluan}

Pengecoran adalah salah satu teknik pembuatan produk dimana logam dicairkan dalam tungku peleburan kemudian dituangkan kedalam rongga cetakan yang serupa dengan bentuk asli dari produk cor yang akan dibuat. Pada saat ini banyak dilakukan penelitian pengecoran logam khususnya aluminium dengan berbagai macam bahan bakar seperti minyak solar, minyak tanah, gas elpiji, batu bara dan sebagainya, baik dikalangan universitas maupun di suatu badan penelitian. Untuk dapat melakukan pengecoran logam maka harus dilengkapi dengan alat peleburan yang mendukung.
Laboratorium adalah tempat belajar mengajar melalui media praktikum yang dapat menghasilkan pengalaman belajar dimana mahasiwa berinteraksi dengan berbagai alat dan bahan untuk mengobservasi gejala-gejala yang dapat diamati secara langsung dan membuktikan sendiri sesuatu yang dipelajari. Dengan adanya kegiatan pembelajaran di laboratorium, mahasiswa dapat mengamati secara langsung dan tidak hanya belajar menurut teori-teori yang ada. Laboratorium juga dapat digunakan sebagai tempat pameran atau display dari hasil-hasil percobaan atau penelitian yang telah dilakukan, agar memberi gambaran lebih bagi mahasiswa dan dapat 
memotivasi untuk penelitian atau percobaan yang lebih baik.

Berdasarkan hal tersebut diatas, penulis mencoba untuk melakukan perencanaan dan pembuatan dapur lebur almunium skala laboratorium dengan kapasitas $20 \mathrm{Kg}$. Rancang bangun dapur lebur bertujuan untuk mendapatkan tipe dapur lebur yang sesuai, menentukan dimensi dapur lebur alumunium, Menentukan bahan dapur lebur dan proses pabrikasi dapur lebur.

\section{Metodologi Penelitian}

Metodologi yang digunakan pada penelitian ini adalah studi literatur dan survey ke lapangan. Dari hasil studi literatur dan survey ke lapangan diperoleh gambaran mengenai dapur lebur yang akan dirancang.

Berdasarkan studi literatur, langkah-langkah yang digunakan untuk melakukan rancang bangun dapur lebur alumunium adalah sebagai berikut:

\section{Pemilihan tipe dapur.}

Pemilihan tipe dapur lebur dilakukan berdasarkan pertimbangan kemudahan teknik pembuatannya, pemilihan bahan bakar yang digunakan dan pertimbangan biaya pembuatan.

\section{Perencanaan Kapasitas Cawan Lebur}

Sesuai dengan perencanaan dimana cawan lebur akan mampu menampung logan cair pada saat operasi peleburan dimana logam cair tidak akan tumpah melebihi ketinggian cawan lebur.

Kapasitas maksimum logam aluminium yang dapat di tampung pada cawan lebur adalah :

$$
\mathrm{W}_{\text {maks }}=\mathrm{V}_{\mathrm{c}} \cdot \rho_{\mathrm{al}}
$$

Dimana :

$$
\begin{array}{ll}
\mathrm{W}_{\text {maks }} & =\text { Kapasitas maksimum cawan } \\
\rho_{\mathrm{a}} & =\text { Berat jenis aluminium } \\
\mathrm{V}_{\mathrm{c}} & =\text { Volume cawan }
\end{array}
$$

3. Perencanaan Dinding Luar Dapur Lebur.

Dinding luar dalam pembuatan dapur, bahan yang dipergunakan yaitu plate baja karbon rendah. Dengan cara melakukan pemotongan drum oil. Ketebalan plate adalah 2,5 mm. Berat dinding luar adalah :

$\mathrm{W}_{3}$ =berat dinding samping+berat dinding atas bawah

$\mathrm{W}_{3}=\pi \cdot \mathrm{D}_{\mathrm{d}} \cdot \mathrm{t} \cdot \mathrm{x}_{\mathrm{dl}} \rho+2 \cdot \pi / 4 \cdot \mathrm{D}_{\mathrm{d}}^{2} \cdot \mathrm{x}_{\mathrm{d} 2} \cdot \rho$

Dimana :

$\mathrm{D}_{\mathrm{d}}=$ Diameter dinding luar

$\mathrm{t}=$ Tinggi dinding luar yaitu

$\mathrm{X}_{\mathrm{d} 1}=$ Tebal dinding samping

$\mathrm{X}_{\mathrm{d} 2}=$ Tebal dinding bawah dan atas

$\mathrm{P}=$ berat jenis dinding $7833 \mathrm{~kg} / \mathrm{m}^{3}$
4. Pemilihan Bahan Dapur Lebur

Pemilihan bahan dapur lebur, meliputi, pemilihan bahan cawan lebur, bahan dapur lebur, Castable yang merupakan bahan yang digunakan untuk pengecoran dinding dapur dan batu tahan api serta semen tahan api.

5. Pabrikasi Dapur Lebur.

Proses pabrikasi merupakan proses pembuatan dapur lebur, yaitu: 1. Pembuatan Cawan pelebur, 2. Pembuatan Dapur lebur.

\section{Hasil dan Pembahasan}

\subsection{Pemilihan Tipe Dapur}

Dalam perancangan ini dipilih dapur pelebur dengan tipe dapur Crucible. Alasan pemilihan dapur lebur tipe crucible adalah :

a. Dapur crucible ini tidak memerlukan teknik pembuatan dan pengoperasian yang terlalu rumit dibanding dapur pelebur jenis lainnya, sehingga cocok digunakan untuk penelitian dan praktikum bagi labortorium foundry.

b. Dapur pelebur $q$ ini dapat menggunakan bahan bakar yang murah seperti gas, minyak tanah, solar dan batu bara.

c. Cocok digunakan untuk melebur logam bukan besi yang mempunyai temperatur cair tidak terlalu tinggi seperti aluminium.

d. Mudah dalam pengoperasiannya terutama untuk pengambilan terak pada logam aluminium.

e. Bahan-bahannya murah dan mudah didapat sehingga biaya pembuatan dapur tidak terlalu tinggi.

Setelah diketahui alasan pemilihan tipe dapur peleburan alumunium yang akan direncanakan, kemudian dibuat model dapur lebur alumunium yang akan direncanakan, seperti terlihat pada Gambar 1 berikut.

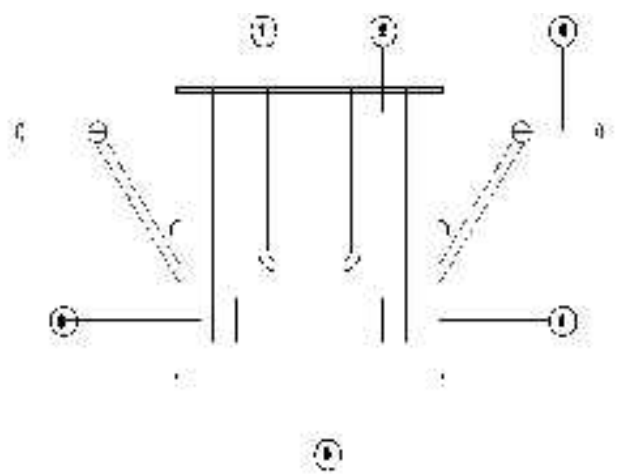

Gambar 1. Gambar Perencanaan Dapur Lebur

Keterangan Gambar:

1. Cawan pelebur

2. Batu Api SK 32

3. Tangkai pengangkat 
4. Plat dinding luar

5. Ruang bakar

6. Dinding dalam

1. Perencanaan Kapasitas Cawan Lebur.

Dengan menggunakan rumus (1), diperoleh kapasitas maksimum cawan lebur adalah 21,69 Kg. Hasil perhitungan tersebut diperoleh dengan mengasumsikan diameter dalam cawan $\left(D_{\text {in }}\right)=180$ $\mathrm{cm}$ dan tinggi cawan $\left(\mathrm{t}_{\text {in }}\right)=315 \mathrm{~cm}$. kapasitas maksimum cawan yang diperoleh masih dibawah kapasitas perencanaan cawan lebur $=20 \mathrm{Kg}$.

\section{Perencanaan Dinding Luar Dapur Lebur}

Dinding luar dalam pembuatan dapur, bahan yang dipergunakan yaitu drum oli yang dipotong. Alasan pemilihannya adalah drum oli merupakan plat baja karbon rendah dengan ketebalan plat adalah 2,5 $\mathrm{mm}$. Dimensi drum oli yang dipotong adalah diameter drum $=0,56 \mathrm{~m}$, tinggi $=0,52 \mathrm{~m}$ dengan ketebalan dinding samping $=0,0025 \mathrm{~m}$ serta ketebalan dinding atas dan bawahnya $=0,003 \mathrm{~m}$. Berdasarkan dimensi drum oli tersebut dan disubsitusikan ke dalam persamaan (2), diperoleh berat dinding luar dapur lebur adalah $29,47 \mathrm{~kg}$.

\section{Pemilihan Bahan Dapur Lebur}

\subsection{Cawan Dapur Lebur}

Fungsi cawan lebur adalah tempat untuk logam cair selama proses peleburan berlangsung. Cawan lebur harus mempunyai titik cair yang jauh lebih tinggi dari titik logam yang akan dilebur. Pada perencanaan ini bahan cawan lebur yang dipakai adalah baja paduan karbon rendah AISI 1310. Pemilihan silinder baja ini sebagai cawan lebur didasarkan bahwa logam yang akan dilebur adalah aluminium dengan temperatur cair $660^{\circ} \mathrm{C}$, sedangkan silinder baja mempunyai titik lebur $1538^{\circ} \mathrm{C}$. Bentuk cawan lebur dapat dilihat pada gambar 2.

Sifat-sifat bahan cawan lebur yang digunakan yaitu :
- Bahan
: Baja paduan karbon rendah AISI 1310
- Titik cair : $1538^{\circ} \mathrm{C}$ atau $1710 \mathrm{~K}$
- Konduktivitas panas : $43 \mathrm{~W} / \mathrm{m}^{\circ} \mathrm{C}$
- Kekuatan tarik : $95 \mathrm{~kg} / \mathrm{mm}^{2}$
- Batas mulur : $40 \mathrm{~kg} / \mathrm{mm}^{2}$
- Kekerasan : $170 \mathrm{H}_{\mathbf{B}}$

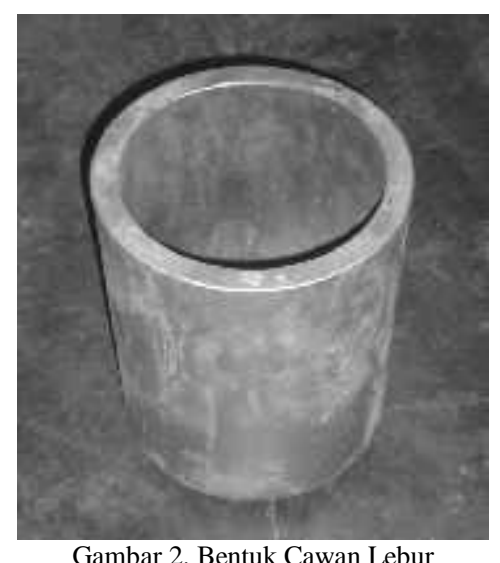

\subsection{Dapur Lebur}

Dapur dalam rancangan ini berfungsi sebagai tempat dimana terjadinya proses pemanasan aluminium. Dalam pembuatan dapur, bahan yang dipergunakan yaitu plate baja karbon rendah. Alasan pemilihan plat baja karbon rendah adalah Mudah diperoleh dipasaran dan Proses pengerjaan tidak terlalu rumit. Berikut ini sifat-sifat dari bahan dapur lebur:

- Bahan : Baja karbon rendah AISI 1109

- Titik cair $\quad: 1538^{\circ} \mathrm{C}$

- Konduktivitas panas : $54 \mathrm{~W} / \mathrm{m}^{\circ} \mathrm{C}$

- Kekuatan tarik : $47 \mathrm{~kg} / \mathrm{mm}^{2}$

- Kekerasan : $103 \mathrm{HB}$

\subsection{Castable}

Castable merupakan bahan yang digunakan untuk pengecoran dinding dapur. Pada perancangan ini, Castable yang digunakan adalah Castable Caj-15. Alasan pemilihan Castable titik cair untuk Castable ini bisa mencapai $1500^{\circ} \mathrm{C}$ atau $1773^{\circ} \mathrm{K}$.

\subsection{Batu Tahan Api dan Semen Tahan Api}

Batu tahan api berfungsi untuk menumpu dan menahan cawan pelebur agar tidak mudah bergetar. Batu tahan api ini mempunyai ketahanan terhadap suhu panas yang tinggi hingga mencapai $1700^{\circ} \mathrm{C}$. Batu tahan api dipasangkan dengan bahan perekat yaitu semen tahan api. Adapun karakteristik kedua bahan tersebut yaitu :

a) Bahan penyekat panas : Batu tahan api SK-32

Ukuran

: $230 \mathrm{~mm} \mathrm{x} 114 \mathrm{~mm} \mathrm{x}$

Titik cair

Konduktivitas panas

$35 \mathrm{~mm}$

Berat jenis $1710^{\circ} \mathrm{C}$ atau $1983 \mathrm{~K}$

: $0,69 \% \mathrm{~W} / \mathrm{m}^{\circ} \mathrm{C}$

: $2,1 \mathrm{~g} / \mathrm{cm}^{3}$ 
b) Bahan pengikat

Titk cair

Konduktivitas panas

Berat jenis

: Semen tahan api SK 32

: $1710^{\circ} \mathrm{C}$ atau $1983 \mathrm{~K}$

: $1,1 \% \mathrm{~W} / \mathrm{m}^{\circ} \mathrm{C}$

$: 1,75 \mathrm{~g} / \mathrm{cm}^{3}$

\section{Pabrikasi Dapur Lebur}

Peralatan yang digunakan pada proses pabrikasi dapat dilihat pada tabel 3.1. berikut:

Tabel 3.1. Peralatan Pabrikasi Dapur Lebur.

\begin{tabular}{|l|l|}
\hline \multicolumn{1}{|c|}{ Nama Alat } & \multicolumn{1}{|c|}{ Kegunaan } \\
\hline Gesin & $\begin{array}{l}\text { Untuk memotong plat dan meratakan } \\
\text { hasil-hasil las dan potongan gerinda }\end{array}$ \\
\hline Mesin Las & $\begin{array}{l}\text { Untuk menyambung besi atau pelat } \\
\text { pada saat membuat rangka }\end{array}$ \\
\hline Meteran & $\begin{array}{l}\text { Digunakan untuk mengukur panjang } \\
\text { atau lebar }\end{array}$ \\
\hline Siku & $\begin{array}{l}\text { Digunakan untuk mengukur tegak } \\
\text { lurus tiang dan sambungan }\end{array}$ \\
\hline Gergaji & Digunakan untuk memotong bahan \\
\hline Plywood & Digunakan sebagai mal \\
\hline Raskam & $\begin{array}{l}\text { Digunakan untuk pengaduk bahan } \\
\text { cor }\end{array}$ \\
\hline Amplas & $\begin{array}{l}\text { Digunakan untuk menghaluskan } \\
\text { permukaan }\end{array}$ \\
\hline
\end{tabular}

Sedangkan bahan-bahan yang digunakan pada proses pabrikasi dapur lebur dapat dilihat pada tabel 3.2. berikut

\begin{tabular}{|l|l|}
\multicolumn{3}{|c|}{ Tabel 3.2 Bahan Pabrikasi Dapur Lebur } \\
\hline Nama Bahan & \multicolumn{1}{|c|}{ Kegunaan } \\
\hline Drum & $\begin{array}{l}\text { Sebagai rangka dasar pembentukan } \\
\text { dapur lebur }\end{array}$ \\
\hline $\begin{array}{l}\text { Batu Api } \\
\text { SK32 }\end{array}$ & $\begin{array}{l}\text { Sebagai dudukan dan penahan } \\
\text { cawan lebur }\end{array}$ \\
\hline $\begin{array}{l}\text { Semen api } \\
\text { SK32 }\end{array}$ & $\begin{array}{l}\text { Sebagai bahan perekat batu api } \\
\text { SK32 }\end{array}$ \\
\hline Castable & Sebagai bahan cor \\
\hline $\begin{array}{l}\text { Besi pipa 2 } \\
\text { inc }\end{array}$ & Sebagai tangkai pengangkat \\
\hline
\end{tabular}

Adapun langkah-langkah dalam pembuatan dapur lebur aluminium sebagai berikut :

1. Pembuatan Cawan pelebur

Pembuatan cawan pelebur ini dengan menempah, ukuran diameter luar $220 \mathrm{~mm}$, diameter dalam $180 \mathrm{~mm}$, tebal dinding 20 $\mathrm{mm}$, dan tingginya $355 \mathrm{~mm}$.

2. Pembuatan Dapur lebur

- Memotong plat drum diameter $560 \mathrm{~mm}$ setinggi $520 \mathrm{~mm}$

- Memotong besi pipa diameter $49 \mathrm{~mm}$ dengan panjang $160 \mathrm{~mm}$ sebanyak 1 buah 130 sebanyak 2 buah

- Menggerinda besi pipa dan drum yang sudah dipotong
- Kemudian menyambung besi pipa keplat drum dengan cara pengelasan

- Memasang anker pada plat drum bagian dalam sebagai penahan agar Castable yang sudah dicor tidak mudah retak atau pecah

- Mencampur Castable dengan air dengan perbandingan $2: 1$ hingga campuran merata

- Melakukan pengecoran keliling plat drum dan lantai plat drum bagian dalam dengan ketebalan cor $70 \mathrm{~mm}$

- Memasang batu api SK32 diatas lantai dapur yang sebelumnya telah dicor Castable

- Memasang batu api SK32 di dinding coran sebagai penahan cawan lebur agar cawan lebur tetap presisi saat pemindahan dan proses peleburan

- Melakukan proses akhir dengan cara pengamplasan di semua bagian-bagian yang tidak rata

- Mengecat bagian-bagian luar dapur lebur.

Gambar hasil rancang bangun dapur lebur alumunium dengan kapasitas $20 \mathrm{~kg}$ dapat dilihat pada gambar 3, berikut

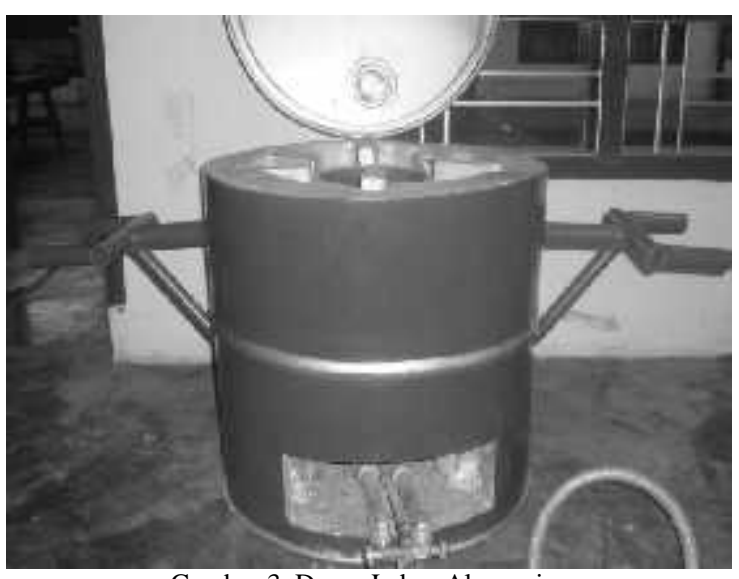

Gambar 3. Dapur Lebur Alumunium

\section{Kesimpulan dan Saran}

\subsection{Kesimpulan}

Berdasarkan alasan-alasan pemilihan dapur lebur, maka diperoleh

1. Jenis dapur

- Dapur yang digunakan adalah dapur pelebur jenis crusibel

- Sumber panas yang digunakan oleh dapur untuk mencairkan aluminium berasal dari kompor dengan bahan bakar minyak tanah.

2. Cawan lebur

$\begin{array}{lll}\text { - } & \text { Bahan } & \begin{array}{c}\text { : Baja paduan karbon } \\ \text { rendah AISI1310 }\end{array} \\ \text { - } & \text { Tinggi cawan } & : 355 \mathrm{~mm} \\ \text { - } & \text { Diameter cawan } & : 220 \mathrm{~mm} \\ \text { - } & \text { Tebal cawan } & : 20 \mathrm{~mm} \\ \text { - } & \text { Kapasitas peleburan }: 20 \mathrm{~kg}\end{array}$


3. Dimensi dapur

- Bahan

:Baja paduan karbon rendah AISI1109

- $\quad$ Diameter dinding luar :560 mm

- Tebal dinding luar $\quad: 2,5 \mathrm{~mm}$

- $\quad$ Tinggi Dapur $\quad: 520 \mathrm{~kg}$

4. Bahan tahan api

- Batu tahan api SK-32

Ukuran :

$\begin{array}{ll}\text { Panjang } & : 230 \mathrm{~mm} \\ \text { Lebar } & : 114 \mathrm{~mm} \\ \text { Tebal } & : 35 \mathrm{~mm}\end{array}$

- Bahan pengikat semen api SK-32

- Castable CAJ-15 Jarefu

\subsection{Saran}

Untuk lebih menyempurnakan pembahasan mengenai perancangan dan pabrikasi ini adalah :

1. Dilakukan pengujian terhadap hasil pabrikasi yang telah dilakukan.

2. Dilakukan analisa kebutuhan bahan bakar terhadap hasil rancang bangun yang telah dikerjakan.

\section{Daftar Pustaka}

[1] B. H. Amstead, Sriati. 1989. Teknologi Mekanik, Jilid 1. Erlangga, Jakarta.

[2] F.A. Lewis. 1976. Aluminium Allow Casting and Foundry. Jhon Willey and Sons, New York

[3] George E. Dieter. 1986. Metalurgi Mekanik, Jilid 2. Erlangga, Jakarta.

[4] Holman, J.P. 1986. Perpindahan Kalor. Erlangga, Jakarta.

[5] Joseph E. Shingley. 1986. Perencanaan Teknik Mesin. Erlangga, Jakarta

[6] Lithel Richard. 1982. Metal Working Technology. McGraw Hill, Inc. New York.

[7] Tata Surdia, Shinroku Saito. 1995. Pengetahuan Bahan Teknik. PT. Pradnya Paramita, Jakarta.

[8] Tata Surdia, Kenji Chijiwa. 1995. Teknik Pengecoran Logam. PT. Pradnya Paramita, Jakarta. 